\title{
A prática da compostagem como instrumento no ensino de conteúdos e na Educação Ambiental Crítica
}

\author{
The practice of composting as an teaching instrument of curriculum content and Critical \\ Environmental Education
}

Aldineia Buss ', Charles Moreto"

\section{Resumo}

A compostagem consiste em uma técnica na qual se faz o controle da decomposição de restos vegetais resultando no composto orgânico. Além dos muitos benefícios dessa técnica para o ambiente, aqui, pensou-se a compostagem como um possível instrumento de ensino. Desse modo, este trabalho objetivou avaliar o uso da prática da compostagem como um instrumento no ensino de conteúdos exigidos no currículo e/ou no desenvolvimento da Educação Ambiental (EA). Para isso, fez-se uma avaliação da produção acadêmica, no período entre 2010 e 2018 , que relata a prática da compostagem nesse sentido, além de desenvolver essa prática com estudantes em uma escola na educação básica. Todos os artigos levantados avaliaram de forma positiva o uso da compostagem como instrumento ou método na EA, bem como nas disciplinas que envolveram em seus projetos. Os resultados obtidos a partir do desenvolvimento prático mostraram que os alunos construíram e ampliaram conhecimentos, além de terem aumentado sua percepção dos problemas ambientais. Assim, essa prática se mostra capaz de contribuir para a aprendizagem significativa, que permite superar as concepções alternativas para construir o conhecimento científico, além de proporcionar a compreensão de aspectos ambientais importantes para a prática da cidadania ambiental.

Palavras-chave: Compostagem; Instrumento de ensino; Educação Ambiental; Educação básica

\section{Abstract}

Composting consists of a technique in which the decomposition of vegetable remains is controlled, resulting in the organic compound. In addition to the many benefits of this technique for the environment, here composting was thought as a teaching tool. Thus, this work aimed to evaluate the use of composting practice as an instrument in the content education required in the curriculum and / or in the development of Environmental Education (EE). For this, an evaluation of the academic production, which reports on the practice of composting in this meaning, was made in the period between 2010 and 2018, and this practice was developed with students at school in basic education. All the articles surveyed had positively evaluated the use of compost as an instrument or method in the EE, likewise in the disciplines that involved in their projects. The results obtained from the practical development showed that the students constructed and expanded knowledge, besides increasing theirs perception of environmental problems. Thus, this practice is capable of contributing to meaningful learning, which allows to overcome alternative conceptions for to build scientific knowledge, apart from to provide an understanding of important environmental aspectsfor the practice of environmental citizenship.

Keywords: Composting; Teaching instrument; Environmental Education; Basic education 


\section{Introdução}

Os Resíduos Públicos Urbanos (RPU), incluindo os Sólidos Domiciliares Orgânicos (RDO), são produzidos numa média de $0,95 \mathrm{~kg} /$ habitante/dia. Dos resíduos que vão para disposição final, $63 \%$ têm destinação em aterros sanitários, 8,1\% em aterros controlados, 9,7\% em lixões, $5 \%$ vão para unidades de triagem, 1,6\% representa os recicláveis secos e $0,4 \%$ são compostados, $19,1 \%$ não se tem informações (SNIS, 2017). Em torno de 70\% do total dos RDO+RPU representa massa de matéria orgânica e rejeitos (SNIS, 2017).

Os Resíduos Sólidos Orgânicos (RSO) representam grande preocupação para a administração pública, já que, comumente são destinados para aterros sanitários onde representam riscos ambientais, além do desperdício de nutrientes (LOES, 2010). Para Costa et al., (2015) a compostagem poderia reduzir em $50 \%$ o problema do lixo. Essa técnica consiste na decomposição controlada de restos vegetais, resultando em um material similar ao solo orgânico, o composto orgânico. Tal método proporciona, além de um destino adequado aos RSO, diversas vantagens como: o melhor aproveitamento da matéria orgânica, reduzindo as perdas de nutrientes; a desinfecção dessa matéria; a recuperação de solos, o composto favorece o enraizamento e o crescimento de plantas, melhora a infiltração, a retenção e a circulação de água e diminui a erosão; substitui o adubo químico, dentre outras contribuições para um ambiente equilibrado (PENTEADO, 2010).

Além dos muitos benefícios da compostagem para o ambiente, entende-se aqui a compostagem como uma possível ferramenta na Educação Ambiental Crítica (EAC), bem como no ensino de conteúdos exigidos no currículo. A problemática envolvendo os resíduos sólidos pode ser um tema gerador de diversas perguntas para a interpretação da realidade vivida, e um método lúdico na contextualização de conteúdos.

A Educação Ambiental Crítica é a vertente da Educação Ambiental (EA) que visa formar o indivíduo na sua consciência plena sobre o meio do qual faz parte, sobre as causas e consequências da organização social no meio (GUIMARÃES, 2004). A EAC não está preocupada apenas com a preservação de espécies biológicas e com o equilíbrio biológico dos ecossistemas, que são aspectos importantíssimos, mas ela vai muito além disso, objetiva a reflexão das relações políticas, sociais, econômicas e culturais entre humanidade e natureza e as relações entre os seres humanos, no sentido de proporcionar aos indivíduos, o exercício da livre cidadania, capacitandoos a participem ativamente na busca de soluções que permitam a convivência digna de todas as espécies biológicas (REIGOTA, 2018). A importância da EA está reconhecida em vários documentos oficiais em todo o mundo, destacando-se a Lei № 9.795/99 que dispõe sobre a Política Nacional de Educação Ambiental e determina que a EA deve ser trabalhada em todos os níveis e modalidades do processo educativo (CASA CIVIL, 1999).

No ensino de conteúdos, o trabalho com compostagem na escola pode ser uma opção interessante no desenvolvimento de aulas práticas sobre o ciclo da matéria orgânica, microrganismos, solo, etc. Diversos autores discutem a importância das aulas práticas que podem contribuir para uma melhor compreensão dos processos das ciências no ensino de conteúdos diversos (HODSON, 1988; GALIAZZI \& GONÇALVES, 2004; ROSITO, 2008). Penick (1998), ressalta que para os alunos desenvolverem habilidades necessárias à alfabetização científica, faz-se necessário que eles tenham papel ativo na aprendizagem, tendo visto que o modelo de aula tradicional passiva pouco tem contribuído para esse processo.

Assim, este trabalho objetivou avaliar o uso da prática da compostagem como um instrumento de ensino de conteúdos e/ou no desenvolvimento da Educação Ambiental. Para isso, fez-se um levantamento de artigos, publicados no período entre 2010 e 2018 que relatam e avaliam a experiência da utilização da compostagem nesse sentido, compilando a conclusão dos autores e avaliando se essas práticas contribuem na construção de novos conhecimentos e de uma consciência ambiental crítica pelos educandos. Além disso, desenvolveu-se essa prática com alunos da educação básica, fazendo a mesma avaliação.

\section{Material e Métodos}

Para atender ao objetivo proposto, fez-se um levantamento de artigos publicados no período entre 2010 e 2018, utilizando os descritores "educação ambiental e compostagem" "educação ambiental" e "compostagem". Foram realizadas buscas no portal de periódicos CAPES/MEC e no Google Acadêmico. Dos documentos levantados, foram selecionados aqueles que relatam e avaliam a experiência da utilização da compostagem como um instrumento no ensino de conteúdos e/ou no desenvolvimento da EA em escolas da educação básica. Após a seleção dos documentos, as informações obtidas foram organizadas e discutidas.

A prática de compostagem, por sua vez, foi desenvolvida em uma classe de $5^{\circ}$ ano das séries iniciais, com 18 alunos, na Escola Municipal de Ensino Fundamental São Marcos, situada no bairro São Marcos, no município da SerraES, Brasil. As atividades foram desenvolvidas durante o segundo trimestre e parte do terceiro do calendário letivo, compreendendo o período de maio a agosto de 2017. Inicialmente, em aula dialogada, procurou-se instigar os alunos a pensar sobre os problemas ocasionados pelo lixo, o porquê da sua produção excessiva e as possíveis soluções para tais problemas. Posteriormente foram discutidos o histórico da relação homem-natureza, o instante em que essa relação passa a ser muito mais antropocêntrica, no sentido de enxergar a natureza como fonte de recursos, o que ocorre a partir da Revolução Industrial; o crescimento populacional; a demanda por recursos; o consumismo; a produção excessiva de lixo; a sua destinação inadequada; os problemas decorrentes e as possíveis soluções a partir da política dos $5 \mathrm{Rs}$ e, de forma mais pontual, a compostagem como uma maneira de reciclar os Resíduos Sólidos Orgânicos (RSO), assim 
como as demais vantagens dessa técnica e de seu produto, o composto.

Na sequência, os alunos foram envolvidos em uma aula prática, onde foi confeccionada uma composteira caseira, reaproveitando dois baldes de margarina que tiveram o fundo furado para a liberação do chorume e foram acoplados um encima do outro, tendo o de cima furos na parte superior para a aeração o e o debaixo a tampa com abertura. Os RSO usados foram os provenientes da cozinha da escola. Após a confecção da composteira, os estudantes observaram as etapas de decomposição objetivando a compreensão da ciclagem orgânica e da importância dos microrganismos responsáveis por esse processo. Essa etapa foi acompanhada a partir de visitas semanais à composteira, fazendo registros escritos e desenhados do processo. Ao final da compostagem, algumas possibilidades de uso do composto foram apresentadas aos alunos, sendo uma delas, o cultivo de flores em vaso, desenvolvida por eles. Nessa etapa foram utilizadas sementes de uma planta ornamental, terra obtida no quintal da escola, vasos plásticos, pás e regador.

No decorrer do desenvolvimento do projeto diversas atividades, sendo elas, discussão oral, leitura, escrita e resolução de problemas matemáticos foram feitas, de forma a contemplar e inter-relacionar as disciplinas de Língua Portuguesa, Matemática, Ciências, História e Geografia.

Para avaliar os conhecimentos dos alunos sobre o assunto e a percepção ambiental acerca da problemática ambiental causada pelos Resíduos Sólidos com enfoque nos Resíduos Sólidos Orgânicos, foi aplicado um mesmo questionário antes e após o desenvolvimento das atividades. Os dados dos questionários foram analisados de maneira qualitativa, e quantitativa em percentuais utilizando o software Microsoft Excel. As respostas das questões discursivas foram agrupadas em categorias, conforme Bardin, (1977).

\section{Resultados e Discussão}

\subsection{De que forma a compostagem como instrumento de ensino vem sendo desenvolvida nas escolas}

Dos artigos levantados (Tabela 1), dezesseis atenderam aos quesitos propostos e foram selecionados para a revisão. Todos os trabalhos foram realizados no âmbito escolar envolvendo: alunos e professores (12); alunos e suas famílias (1); alunos, professores, outros funcionários da escola e a comunidade (3). E foram desenvolvidos em diferentes etapas do ensino, sendo 11 no ensino fundamental e cinco no ensino médio.

A EA aparece como objetivo em todos os trabalhos, exceto Silva et al. (2015), sendo que oito deles envolveram disciplinas do currículo educacional (Tabela 1). Isso evidencia a aplicabilidade da compostagem como um instrumento em diversos ramos do conhecimento e vem ao encontro da proposta dos Parâmetros Curriculares Nacionais (PCNs) que incluem o tema Meio Ambiente no currículo como um tema transversal. A questão ambiental necessita do conhecimento de diversas áreas. A transversalidade aponta para uma prática educativa que estabeleça uma relação do aprendizado dos conhecimentos sistematizados com a realidade, com os saberes extraescolares e propõe a interdisciplinaridade, ou seja, a inter-relação entre as disciplinas do currículo (MINISTÉRIO DA EDUCAÇÃO, 2001).

Tabela 1 - Artigos selecionados, disciplinas envolvidas e se a interdisciplinaridade foi objetivada

\begin{tabular}{|c|c|c|}
\hline Autor/ano & Disciplinas & Objetivou a interdisciplinaridade? \\
\hline Loes, 2010 & - & Não \\
\hline Costa \& Silva, 2011 & Geografia, Ciências Naturais & Multidisciplinar \\
\hline Costa \& Silva, 2012 & - & Não \\
\hline Souza et al., 2013 & - & Não \\
\hline Santos et al., 2014 & Ciências & Não \\
\hline Beco et al., 2014 & - & Não \\
\hline Costa et al., 2015 & Química & Sim \\
\hline Silva et al., 2015 & $\begin{array}{l}\text { Língua Portuguesa, Matemática, Biologia } \\
\text { Sociologia, Gestão Ambiental, Ciências Agrárias }\end{array}$ & $\operatorname{sim}$ \\
\hline Magnago et al., 2015 & Biologia, Matemática, Química, Física. & $\operatorname{sim}$ \\
\hline Demarco et al., 2015 & - & Não \\
\hline Bianchini et al., 2015 & - & Não \\
\hline Mattos et al., 2015 & - & Não \\
\hline Lima \& Lima, 2016 & Ciências & Não \\
\hline Santos et al., 2016 & - & Não \\
\hline Lustosa et al., 2017 & Ciências & Não \\
\hline Mallmann et al., 2018 & Ciências, Filosofia, Química & Multidisciplinar \\
\hline
\end{tabular}


As problemáticas ambientais devem ser trabalhadas em diversas áreas do conhecimento, como observado nos relatos dos artigos avaliados, entretanto, para que a EA alcance seus objetivos, de formação de um novo agir social, se propõe que a temática seja desenvolvida sob a perspectiva da interdisciplinaridade, dada a amplitude dessa formação (PEREIRA, 2014), como estabelece o Tratado de Educação Ambiental para Sociedades Sustentáveis e Responsabilidade Global (FÓRUM DAS ORGANIZAÇÕES NÃO-GOVERNAMENTAIS, 1992), do qual o Brasil é signatário, "A educação ambiental deve envolver uma perspectiva holística, enfocando a relação entre o ser humano, a natureza e o universo de forma interdisciplinar".

Dentre os trabalhos avaliados, apenas três apresentaram a interdisciplinaridade como um objetivo e dois desenvolveram suas atividades de forma multidisciplinar (Tabela 1). Magnago et al. (2015) desenvolveu diversas atividades práticas, sendo a compostagem uma delas, trabalhando de forma interdisciplinar conceitos das disciplinas de Matemática, Biologia, Química e Física. O trabalho de Silva et al. (2015) envolveu os alunos no planejamento das atividades de modo a comtemplar as disciplinas de Química, Biologia, Língua Portuguesa, Matemática, Sociologia, Gestão Ambiental e Ciências Agrárias, dando a cada uma um enfoque específico, segundo os autores, sem perder, a essência do enfoque global viabilizado no diálogo entre todas.

A escolha do tema ocorreu durante uma reunião com os próprios alunos. A sugestão levou em consideração a relevância da compostagem para o serviço do técnico em agropecuária e que este necessitava não apenas de conhecimento químico. Após a decisão, eles fizeram uma relação de possíveis disciplinas que poderiam dar sua colaboração com a prática (português, matemática, sociologia, gestão ambiental, ciências agrárias etc.) (SILVA et al., 2015, p. 78).

Todos os trabalhos enfatizam a compostagem como um instrumento prático, capaz de romper com as aulas unicamente tradicionais, buscando a articulação entre teoria e prática, de forma crítica e investigativa. Costa et al. (2015), na perspectiva do ensino de Química, afirma que a reprodução isolada do conhecimento químico, sem a prática investigativa, é insuficiente para uma aprendizagem satisfatória.

Outro ponto a ser observado, é a predominância da disciplina de Ciências no desenvolvimento das atividades expostas nos artigos. Pereira (2014), avalia que, na prática, a educação ambiental escolar é desenvolvida individualmente por professores de disciplinas isoladas, via de regra, Ciências, Biologia e Geografia, ou por meio de projetos multidisciplinares simples, onde cada professor trabalha a temática sob a ótica de sua disciplina, sem alcançar relação com outras áreas, o que não atinge uma abordagem interdisciplinar, tampouco a complexidade a que se propõe a EA. Segundo Tristão (2008), isso ocorre devido a duas importantes causas: a dificuldade prática de superar o tradicional modelo curricular cientificista, já há muito tempo consolidado, e o déficit na formação inicial e continuada dos professores, que comumente ocorre de forma fragmentada e reducionista, não contemplando os aspectos da interdisciplinaridade.

Ainda relacionado ao instrumento de ensino aqui tratado, Costa \& Silva (2011) e Costa et al. (2015) destacam as concepções alternativas como algo a ser observado nas atividades práticas de compostagem. As concepções alternativas podem ser entendidas como um conjunto de ideias ou conhecimentos prévios adquiridos em aprendizagens anteriores, em contexto formal e não formal que podem ou devem ser utilizados como ponto de partida para novas aprendizagens (ARAÚJO et al., 2011). Costa et al. (2015), salientam que o professor deve identificar as concepções alternativas a fim de prepararse para as aulas. Para Costa \& Silva (2011), a utilização da compostagem como recurso metodológico é uma maneira dinâmica e interdisciplinar onde os educandos têm a oportunidade de romper com suas concepções alternativas para a construção de conhecimentos científicos.

Outros trabalhos, aqui avaliados, se destacam por promover a EA para além dos espaços escolares, envolvendo, de alguma forma, a comunidade, como o projeto relatado por Santos et al. (2016) e os desenvolvidos por Costa \& Silva (2012) e Demarco et al. (2015). Nesse sentido, Guimarães (2007) chama a atenção para a importância de superar a separação entre educação formal (escolar) e não-formal ultrapassando os muros da escola, de forma a dialogar com a realidade socioambiental, uma vez que, na interação com a comunidade, é possível aplicar os conhecimentos adquiridos na escola na interpretação da realidade vivida, gerando um novo conhecimento capaz de impulsionar transformações no indivíduo e na sociedade, de forma que o indivíduo promova mudanças na sociedade e a sociedade no indivíduo.

Outro ponto importante a ser discutido, é o que assegura a legislação referente à EA, devendo essa ser desenvolvida em todas as etapas do ensino. Em relação a isso, o trabalho de Beco et al. (2014) desenvolvido na educação infantil, no ensino fundamental e médio, exemplifica que a compostagem como um instrumento de ensino pode ser adaptada para essas diversas etapas, adequando-se os conteúdos e a didática envolvidos.

Em síntese, todos os trabalhos avaliam como positivo o uso da compostagem como instrumento ou método na EA, bem como no ensino de diversas disciplinas e corroboram entre si, que a prática da compostagem proporciona o desenvolvimento de atividades transversais e interdisciplinares, promove a associação ensino/pesquisa a partir da atividade prática que envolve a observação dos fenômenos, discussões dos resultados e registro, resultando em aprendizagens relevantes e significativas. Entretanto, apesar de quase todos os trabalhos terem objetivado a EA, poucos deles procuram discutir as causas dos problemas ambientais, nesse caso, a problemática dos resíduos sólidos. Nessa direção, apenas Mallmann et al. (2018) e Costa \& Silva (2012) buscam proporcionar, segundo eles, uma discussão crítica sobre o modelo capitalista relacionado a produção de resíduos orgânicos e desperdício de recursos naturais. A maioria dos trabalhos, como afirma Guimarães (2007), parecem estar centrados 
na busca de soluções para problemas locais, o que é muito importante, mas não satisfaz a necessidade de contextualizar esses problemas em um âmbito global, proporcionando reflexões mais profundas sobre a relação homem-natureza. A Educação Ambiental Critica envolve, necessariamente, as dimensões políticas, econômicas e sociais das questões ambientais (DIAS, 2001).

\subsection{Testando a compostagem como um instrumento de ensino: uma abordagem prática}

O projeto desenvolvido procurou envolver as disciplinas do currículo, como já descrito, de forma a promover a interdisciplinaridade e a contextualização local e global dos assuntos propostos, dando sentido ao que é ensinado/aprendido. Além disso, adequou-se os conteúdos e as atividades a estrutura cognitiva de conhecimento dos alunos, de forma a propiciar que os novos conhecimentos fossem relacionados aos já construídos, visando alcançar a aprendizagem significativa (AUSUBEL, 1968) e a EAC. Dezoito estudantes, com idade entre 10 e 14 anos, participaram da pesquisa (Tabela 2).

As avaliações do conhecimento dos alunos, prévios e posteriores às atividades, mostraram que, sobre o conceito de lixo (Figura 1A), para a maioria dos estudantes (56\%) no período anterior ao projeto, o lixo é algo sem utilidade. A partir daí, procurou-se leva-los à reflexão de que de fato é esse o conceito de lixo, mas que se esse algo sem utilidade pode tornar-se útil, e então deixa de ser lixo, o que remete ao conceito de reciclagem. $O$ conceito de "algo sem utilidade" também foi o mais citado, conforme pesquisa de Cavalcante et al. (2012). Quanto ao conhecimento sobre lixo orgânico e não orgânico, cresceu o número de alunos que têm o conceito mais adequado a respeito do assunto (Figura $1 \mathrm{~B}$ e C). Também passou de $6 \%$ para $33 \%$ dos alunos que passaram a conhecer mais sobre a reciclagem, apesar de a maioria ainda não compreendê-la adequadamente (Figura 1D).

Houve também um aumento expressivo no percentual de alunos conscientes da quantidade de lixo produzida por pessoa e do destino dado a ele. Além disso, muitos passaram a se preocupar com o destino do lixo produzido bem como, a ter atitudes para diminuir sua produção (Tabela 3). Adquirir consciência do meio local e global e dos problemas ambientais, são finalidades essenciais da EA (DIAS, 2001).

Quando questionados sobre o que poderia ser feito para diminuir a produção de lixo, somente $22 \%$ e $67 \%$ dos alunos, anterior e posterior ao projeto respectivamente, citaram atitudes condizentes. No período anterior $50 \%$ dos alunos disse não saber e $22 \%$ citou ações referentes à limpeza dos ambientes (Figura 2A), o que revela a necessidade desse tema estar presente na escola. Quanto as possíveis atitudes para reduzir os problemas causados pelo lixo, passou de $33 \%$ para $80 \%$ dos alunos que citaram ações favoráveis, nos períodos anterior e posterior respectivamente (Figura $2 \mathrm{~B}$ ).

Posterior ao projeto, $80 \%$ dos educandos soube descrever a importância da reciclagem, comparado a $34 \%$ no período anterior (Figura $3 \mathrm{~A}$ ), e $67 \%$ passou a assumir o processo de compostagem como uma forma de reciclagem dos resíduos orgânicos, considerando-o uma possível solução para diminuir o acúmulo de lixo (Figura 3B). Vale também elencar algumas das muitas vantagens da compostagem que os alunos passaram a observar, como: diminuição dos lixões; redução da poluição do ambiente e das doenças como as transmitidas por mosquitos; e utilidade do composto gerado, na adubação de plantas.

Além dos dados obtidos com os questionários, a observação do comportamento dos alunos permitiu registrar o entusiasmo deles com as atividades ao ar livre, o interesse pelos processos de mudança da matéria orgânica durante a compostagem, a surpresa com o composto como resultado dela e o afeto desenvolvido durante o cultivo das flores e o contato com a terra. Sá (2002, p.46) salienta que o prazer nas atividades de aprendizagem contribui para o envolvimento pessoal e intelectual.

As atividades teórico-práticas, desenvolvidas neste projeto, contribuíram para a construção e/ou ampliação da compreensão de conceitos relacionados à compostagem, ao ciclo da matéria orgânica, além de habilidades como interpretação e produção de textos, tabelas e gráficos e a compreensão do contexto social em que se dá o problema da produção excessiva de resíduos. Tais resultados podem ser atribuídos tanto ao caráter teórico-prático das atividades, ressaltado como eficiente no processo ensino-aprendizagem, como já destacado neste texto, como pelo contato com o meio natural proporcionado por essas atividades. Vaske \& Kobrin (2001), constataram

Tabela 2 - Caracterização dos alunos participantes

\begin{tabular}{llc}
\hline & & Número de alunos \\
\cline { 3 - 3 } Sexo & & \\
\hline & Feminino & 7 \\
\hline Idade & Masculino & 11 \\
\hline & & \\
\hline 10 anos & 9 \\
11 anos & 5 \\
14 anos & 3 \\
\hline
\end{tabular}


Figura 1 - Conhecimento dos alunos sobre conceitos relacionados aos resíduos sólidos antes e após o desenvolvimento do projeto

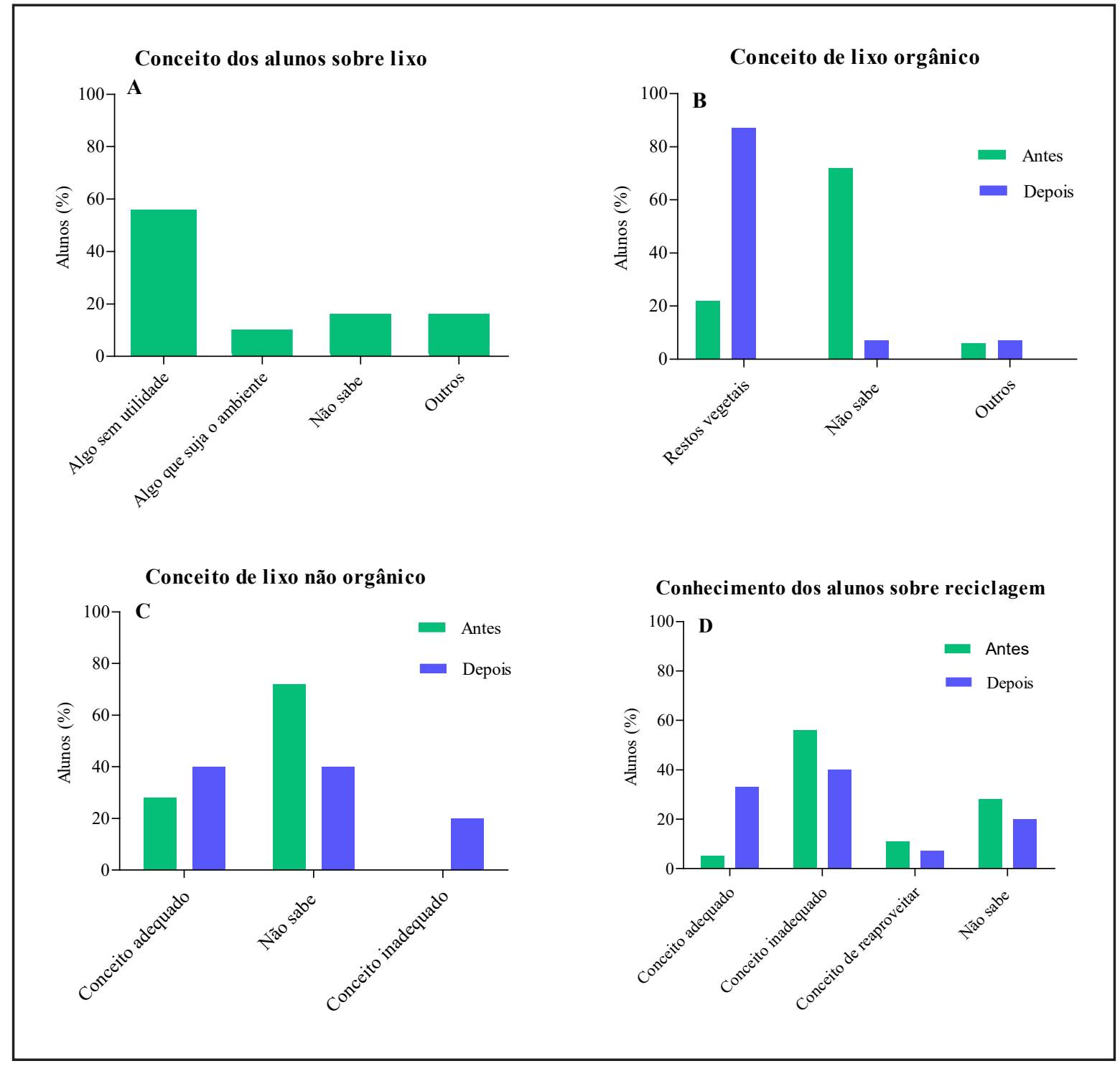

Tabela 3 - Consciência dos alunos sobre lixo antes e após o desenvolvimento do projeto

\begin{tabular}{|c|c|c|c|c|}
\hline & \multicolumn{2}{|c|}{ Antes } & \multicolumn{2}{|c|}{ Depois } \\
\hline & $\operatorname{Sim}$ & Não & Sim & Não \\
\hline $\begin{array}{l}\text { Você sabe qual a quantidade de lixo sólido que uma } \\
\text { pessoa produz por dia? }\end{array}$ & ०\% & $100 \%$ & $67 \%$ & $33 \%$ \\
\hline $\begin{array}{l}\text { Você sabe para onde vai o lixo sólido que é produzido } \\
\text { na sua casa? }\end{array}$ & $50 \%$ & $50 \%$ & $73 \%$ & $27 \%$ \\
\hline $\begin{array}{l}\text { Você se preocupa com o destino do lixo sólido que é } \\
\text { produzido na sua casa? }\end{array}$ & $61 \%$ & $39 \%$ & $80 \%$ & $20 \%$ \\
\hline $\begin{array}{l}\text { Você e sua família têm atitudes para diminuir a } \\
\text { produção de lixo? }\end{array}$ & $28 \%$ & $72 \%$ & $60 \%$ & $40 \%$ \\
\hline
\end{tabular}


Figura 2 - Opinião dos alunos sobre o que poderia ser feito para diminuir a produção de lixo e resolução dos problemas relacionados

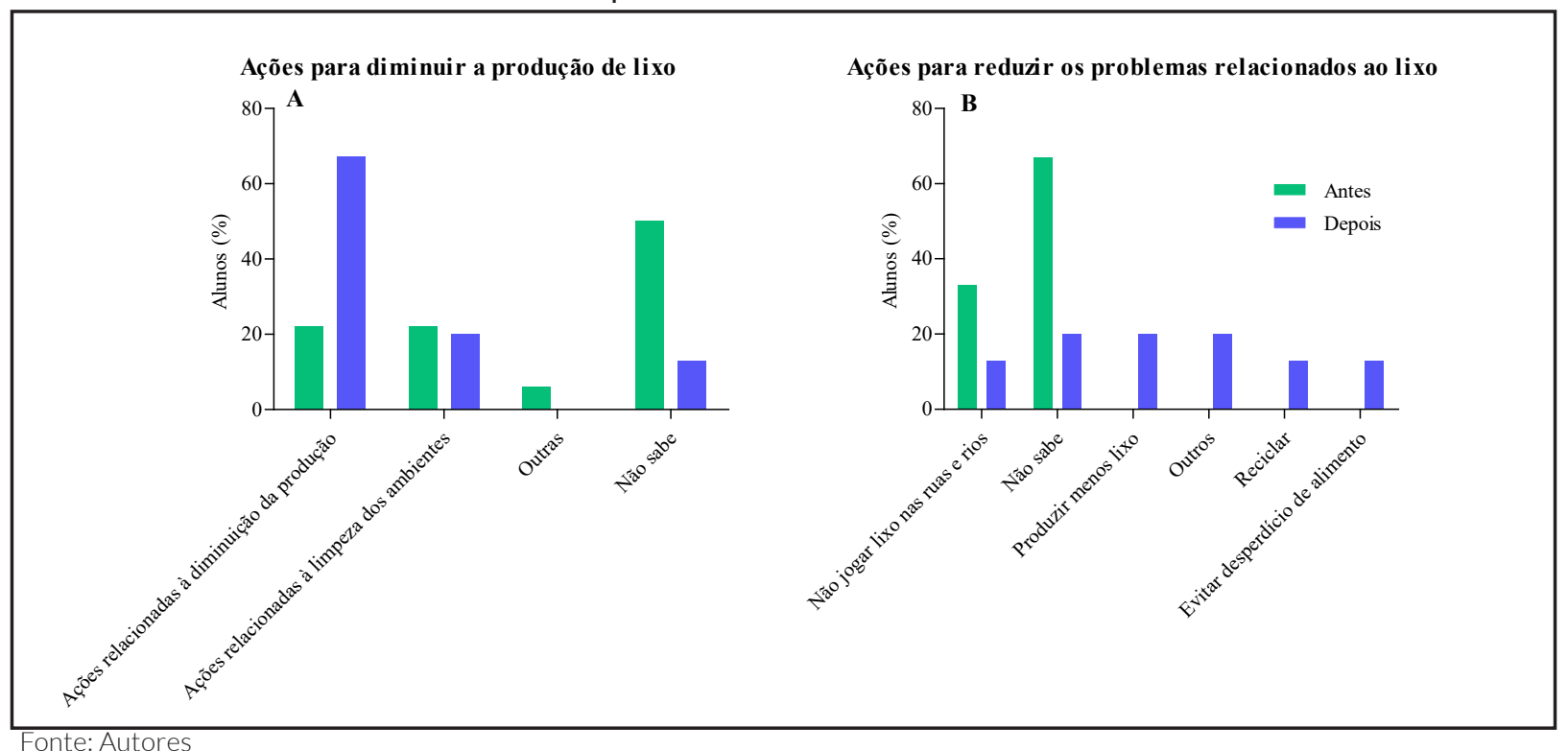

Figura 3 - Conhecimentos dos dos alunos sobre o processo de compostagem e sua aplicação na gestão dos resíduos sólidos

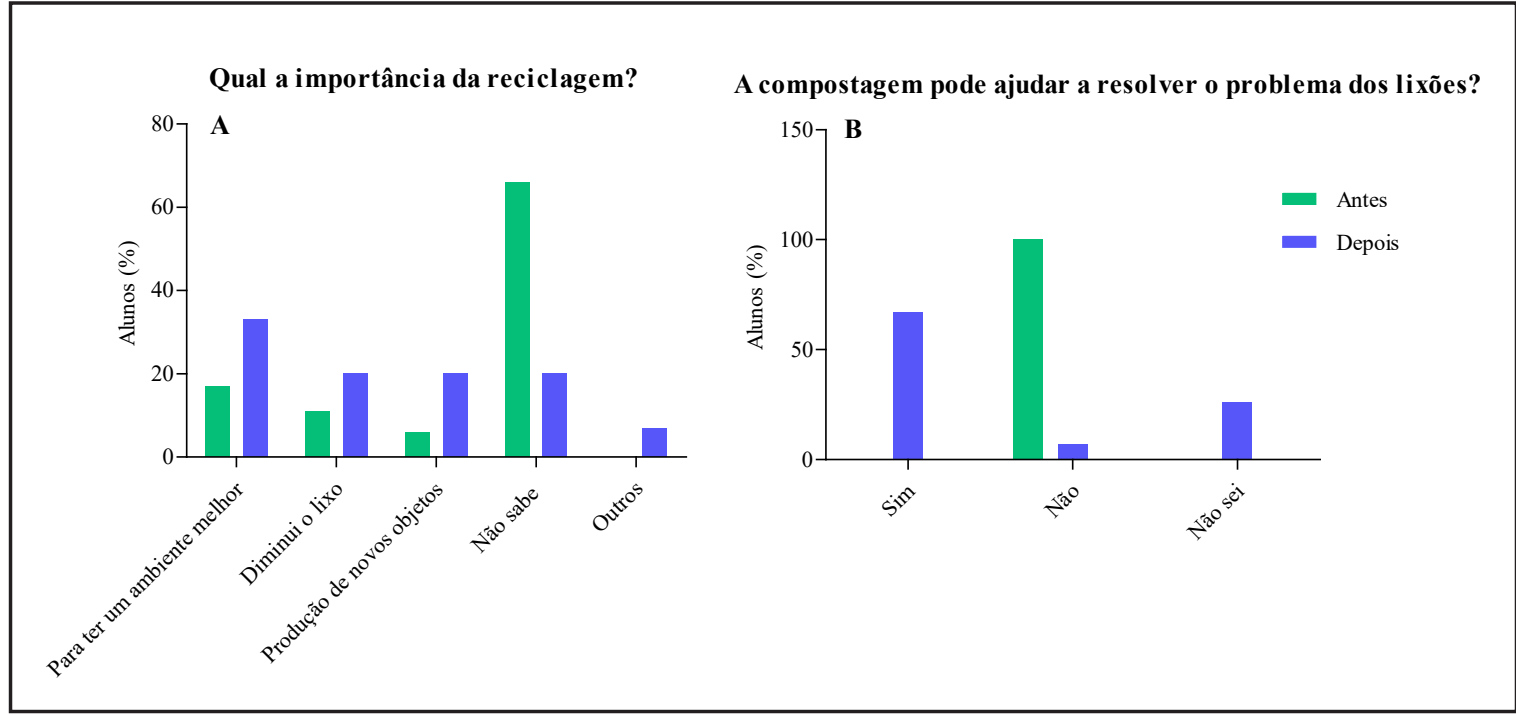

Fonte: Autores

que o contato com um ambiente natural desenvolve o sentimento de identidade local e o que chamaram de “conexão emocional” e que esses sentimentos propiciam o desenvolvimento do comportamento ambientalmente responsável. Além disso, o caráter interdisciplinar das atividades contribui para a compreensão de todo o contexto no qual a problemática trabalhada está inserida.

Conforme Reis et al. (2012), a EA deve buscar métodos que alcancem a mudança de mentalidade dos alunos o que leva a mudanças de atitudes para um comprometimento com um ambiente equilibrado, onde haja harmonia do homem com o meio e com os demais seres vivos. Os autores afirmam ainda, que uma vez que o aluno se torna consciente e sensibilizado em relação ao ambiente, ele também passa a ser um educador ambiental na sua comunidade. Dessa forma, o trabalho da escola pode refletir nas comunidades que a rodeia. Tal mudança de atitude depende do conhecimento, essencial tanto para embasar uma leitura crítica da realidade, quanto para buscar instrumentos para solucionar problemas ambientais (SEGURA, 2001).

Aqui, a prática da compostagem foi desenvolvida não apenas sob o ponto de vista ecológico, mas, principalmente de forma reflexiva sobre o contexto em que ocorre a produção excessiva dos resíduos sólidos. Dessa forma, a prática da compostagem, como um instrumento de ensino, proporcionou aos alunos a construção de novos conhecimentos, bem como, a ampliação da compreensão de aspectos ambientais importantes para a prática da cidadania ambiental, revelando-se um instrumento importante na Educação Ambiental quanto a problemática dos RSO e no ensino de conteúdos do currículo, sendo 
capaz de propiciar a aprendizagem significativa, bem como a construção de uma consciência ambiental crítica. Entretanto, observou-se que a EAC exige um trabalho continuado no decorrer do desenvolvimento cognitivo das crianças, muito porque algumas concepções exigem maior maturidade para serem concretizadas.

\section{Considerações Finais}

Tanto o levantamento bibliográfico, quanto o desenvolvimento prático da utilização da compostagem como um instrumento de ensino, apontam para uma alternativa viável e eficiente no que visa a uma práxis interdisciplinar do processo ensino-aprendizagem, na qual a Educação Ambiental Crítica está ou deveria estar inserida, para a construção de conhecimentos científicos e da consciência ambiental crítica e emancipada.

\section{Agradecimentos}

Agradecemos à Escola Municipal de Ensino Fundamental São Marcos pela recepção do projeto e pelo apoio na sua realização. Também ao Programa Institucional Voluntariado de Iniciação à Docência (Pivid), pela inclusão do projeto no programa, durante a graduação em Ciências Biológicas da primeira autora.

\section{Referências}

ALENCAR MMM. Reciclagem de lixo numa escola pública do município de Salvador. Candombá: Revista Virtual [Internet]. 2005 [cited 2019 feb 18];1(2):96113. Available from: http://revistas.unijorge.edu.br/ candomba/2005v1n2/pdfs/MarileiaAlencar2005v1n2.pdf.

ARAÚJO MFF, Souza RA, Souza IC. Instrumentação para o Ensino de Biologia I. 2st ed. Natal: EDUFRN; 2011.

AUSUBEL DP. [A cognitive theory of school learning]. American Psychological Association, 1968:331-335. English.

BARDIN L. Análise de conteúdo. 70st ed. São Paulo: Persona; 1977.

BECO LAR, LEME PCS, GONÇALVELS D. Atividades de Educação Ambiental: como Minimizar e Lidar com o Resíduo. Rev. Cult. e Ext. USP. [Internet]. 2014 [cited 2019 feb 21];12(12):83-93. Available from: http://www. journals.usp.br/rce/article/view/86806/89805. Doi:10.11606/ issn.2316-9060.v12i0p83-93.
BIANCHINI DC, FANK JC, SEBEN D, RODRIGUES P, RODRIGUES AC. Sustentabilidade e Educação Ambiental na Escola Estadual de Ensino Fundamental Waldemar Sampaio Barros. REMOA-UFSM [Internet]. 2015 [cited 2019 feb 21];188-194. Available from: https:// periodicos.ufsm.br/remoa/article/view/18753/pdf. Doi: 105902/2236130818753.

CASA CIVIL. Lei no 9.795 de 27 de abril de 1999. Dispõe sobre a educação ambiental, institui a Política Nacional de Educação Ambiental e dá outras providências. Brasília (Brasil); Casa Civil; 1999.

MINistéRIO DA EDUCAÇÃO. Parâmetros Curriculares Nacionais - apresentação dos temas transversais: ética. 3st ed. Brasília (Brasil): Ministério da Educação, Secretaria da Educação Fundamental; 2001.

SISTEMA NACIONAL DE INFORMAÇÃO SOBRE SANEAMENTO (SNIS) [Internet]. Diagnóstico do Manejo de Resíduos Sólidos Urbano - 2017. Ministério do Desenvolvimento Regional [cited 2019 mar 27]. Brasília (Brasil): MDR.SNIS; 2019. Available from: http://www. snis.gov.br/diagnostico-residuos-solidos/diagnosticors-2017.

CAVALCANTE LPS, CAVALCANTE LS, MEDEIROS VS, MAIA HJL, ALENCAR LD. Análise da percepção ambiental e sensibilização de educandos do ensino fundamental de uma escola pública para realização da coleta seletiva, campina grande - PB. REMOAUFSM [Internet]. 2012 [cited 2019 feb18];9(9):2047-2054. Available from: https://periodicos.ufsm.br/remoa/article/ view/5967/3906.

COSTA AP, SILVA WCM. A compostagem como recurso metodológico para o ensino de ciências naturais e geografia no ensino fundamental. EnciBio. [Internet]. 2011 [cited 2016 mar 26];7(12). Available from: http://www. conhecer.org.br/enciclop/conbras1/a\%20compostagem.pdf.

COSTA AP, SILVA WCM. Oficinas de compostagem: uma proposta de educação ambiental no IFPB - Campus Cajazeiras e na ASCAMARC. Principia [Internet]. 2012 [cited 2019 feb 21]; (21):57-63. Available from: http:// periodicos.ifpb.edu.br/index.php/principia/article/ view/148. Doi: 10.18265/1517-03062015v1n21p57-63.

COSTA JM, ARAÚJO AT, SILVA BM, ANDRADE LA, ANDRADE RB. Atividade de compostagem em micro escala como forma de promover educação ambiental e saberes em química no ensino médio. Educação Ambiental em Ação [Internet]. 2015 [cited 2016 mar 26];(51). Available from: http://www.revistaea.org/artigo. php?idartigo $=1981$. 
DEMARCO JO, CADORE JS, INSELSPERGER V, RODRIGUES AC, FORTES PR. Extensão Universitária na Conscientização Ambiental em Escolas de Educação Básica. REMOA-UFSM [Internet]. 2015[cited 2019 feb 21];101-107. Available from: https://periodicos. ufsm.br/index.php/remoa/article/view/18747. Doi: $10.5902 / 2236130818747$.

DIAS GF. Educação ambiental: princípios e práticas. 7st ed. São Paulo: Gaia; 2000.

GALIAZZI MC; GONÇALVES FP. A natureza pedagógica da experimentação: uma pesquisa na licenciatura em química. Quim. Nova. [Internet]. 2004 [cited 2019 feb 17];27(2):326-331. Available from: http:// www.scielo.br/pdf/\%0D/qn/v27n2/19283.pdf.

GUIMARÃES M. Educação Ambiental Crítica. In: Layrargues PP, editor. Identidades da educação ambiental brasileira. Diretoria de Educação Ambiental. Brasília: Ministério do Meio Ambiente; 2004. p. 25-34.

GUIMARÃES M. Educação ambiental: participação para além dos muros da escola. In: Mello SS, Trajber R, editores. Vamos cuidar do Brasil: conceitos e práticas em educação ambiental na escola. Brasília: Ministério da Educação, Coordenação Geral de Educação Ambiental, Ministério do Meio Ambiente, Departamento de Educação Ambiental, UNESCO; 2007. p. 85-93.

HODSON D. [Experiments in science and science teaching]. Educational Philosophy and Theory [Internet]. 1988 [cited 2019 feb 17];20(2):53-66. Available from: https:// www.tandfonline.com/doi/abs/10.1111/j.14695812.1988. tb00144.x?journalCode=rept20. English.

LIMA GAA, DIAS CAC, LIMA AH. Compostagem de resíduos sólidos orgânicos como tema incentivador de educação ambiental. Sci. Plena. [Internet]. 2016 [cited 2019 feb 09];12(6). Available from: https://www. scientiaplena.org.br/sp/article/view/3134. Doi:10.14808/ sci.plena.2016.069933.

LOES C. A prática de compostagem no contexto da educação ambiental. Educação Ambiental em Ação [Internet]. 2011 [cited 2016 mar 26]; (34). Available from: http://www.revistaea.org/pf.php?idartigo=954.

LUCENA MMA, FREIRE EMX. [Environmental perception and use of fauna from a Private Natural Heritage Reserve (RPPN) in Brazilian semiarid]. Acta sci., Biol. sci. [Internet]. 2012 [cited 2019 feb 18];34(3):335-341. Available from: https://www.redalyc.org/html/1871/187123686012/. English. Doi: 10.4025/actascibiolsci.v34i3.8763.
LUSTOSA MAFS, SANTOS LA, FREITAS AL, VITAL AFM. Compostagem como proposta didática para falar sobre solos no ensino fundamental. Sci. Plena. [Internet]. 2017 [cited 2019 feb 03];13(12). Available from: $<$ https://www.scientiaplena.org.br/sp/article/view/3907. Doi: $10.14808 /$ sci.plena.2017.121701.

MAGNAGO RF, CUBAS ALV, AGUIAR AN, ROSSATO IF, MOECKE EHS. Ensino Médio Inovador e o Estudo dos Problemas Ambientais. Ciênc. Nat. [Internet]. 2015 [cited 2019 feb 21];37(3):849-861. Available from: https:// periodicos.ufsm.br/cienciaenatura/article/view/17929/ pdf. Doi: 105902/217946017929.

MALLMANN V, ARAGÃO RFR, PESTANA VJ, BARTIERES EMM, ARAGÃO LWR. Educação Ambiental: recursos naturais em transformação, solo e meio ambiente. Realização - Revista de Extensão e Cultura [Internet]. 2018 [cited 2019 feb 21];5(9):3440. Available from: http://ojs.ufgd.edu.br/index.php/ realizacao/article/view/8544/4669. Doi: 10.30612/re-ufgd. v5i9.8544.

MATTOS TM, MULLER NTG, FREITAS N, PACHILA L. Viabilização do Processo de Compostagem na URI/Santo Ângelo-RS, Para a Produção de Plântulas na Educação Ambiental da ONG Eco Global Missões. REMOA-UFSM [Internet]. 2015 [cited 2019 feb 21]:120125. Available from: https://periodicos.ufsm.br/remoa/ article/view/18731/pdf. Doi: 105902/2236130818731.

PENICK JE. Ensinando "alfabetização científica". Educ. rev. [Internet]. 1998 [cited 2019 mar 27];(14):91113. Available from: http://www.scielo.br/scielo. php?pid=S0104-40601998000100007\&script=sci_arttext. Doi: 10.1590/0104-4060.183.

PENTEADO SR. Adubação orgânica: compostos orgânicos e biofertilizantes. 3st ed. São Paulo: Via orgânica Fraga Penteado \& Cia; 2010.

PEREIRA FA. Educação ambiental e interdisciplinaridade: avanços e retrocessos. Brazilian Geographical Journal: Geosciences and Humanities research medium [Internet]. 2014 [cited 2019 feb 18];5(2):575-594. Available from: https:// dialnet.unirioja.es/servlet/articulo? codigo $=4995487$.

REIGOTA MAS. O que é educação ambiental. 2st ed. São Paulo: Brasiliense; 2009.

REIS LCL, SEMÊDO LTAS, GOMES CG. Conscientização Ambiental: da Educação Formal a Não Formal. R. Flu. Exten. Univ. [Internet]. 2012 [cited 2019 feb 18];2(1):47-60. Available from: http://editora. universidadedevassouras.edu.br/index.php/RFEU/article/ view/442/312. 
ROSITO BA. O ensino de ciências e a experimentação. In: Moraes R, editor. Construtivismo e ensino de ciências: reflexões epistemológicas e metodológicas. 3st. ed. Porto alegre: ediPUCRS; 2008. p. 195-208.

SÁ JG. Renovar as práticas do $1^{0}$ Ciclo pela via das ciências da natureza. 2st ed. Porto: Porto Editora; 2002.

SANTOS AM, MARTINS RML, SOUZA R, MOTA RMF, FERNANDES CT. Incentivo ao Uso da Compostagem de Resíduos Sólidos em uma Horta Escolar do Município de Jaciara-MT. Rev. Ens. Educ. Cienc. Human. [Internet]. 2014 [cited 2019 feb 19];15(especial):321-329. Available from: http://pgsskroton. com.br/seer/index.php/ensino/article/view/426/395. Doi: 10.17921/2447-8733.2014v15n0p\%25p.

SANTOS VS, SCHMIT JL, ROSA MD. A Educação Ambiental como potencial para o gerenciamento de resíduos sólidos escolares: o caso da EMEF Boa Saúde, Novo Hamburgo (RS). RevBEA [Internet]. 2016 [cited 2019 feb 21];11(5):53-66. Available from: http://revbea. emnuvens.com.br/revbea/article/view/4940/3211.

SEGURA DSB. Educação ambiental na escola pública: da curiosidade ingênua à consciência política. São Paulo: Annablume; 2001.

SILVA MA, MARTINS ES, AMARAL WK, SILVA HS, MARTINES EAL. Compostagem: experimentação problematizadora e recurso interdisciplinar no ensino de química. Quím. nova esc. [Internet]. 2015 [cited 2016 mar 27];37(1):71-81. Available from: http://qnesc.sbq.org. br/online/qnesc37_1/12-EEQ-38-14.pdf. Doi: 10.5935/01048899.20150011 .

SOUZA GS, MACHADO PB, REIS VR, SANTOS AS, DIAS VB. Educação Ambiental como ferramenta para o manejo de resíduos sólidos no cotidiano escolar. RevBEA [Internet]. 2013[cited 2019 feb 18]; 8(2):118-130. Available from: http://www.sbecotur.org.br/revbea/index. php/revbea/article/view/2443/2638.

FÓRUM DAS ORGANIZAÇÕES N ÃOGOVERNAMENTAIs[ Internet]. Tratado de Educação Ambiental para Sociedades Sustentáveis e Responsabilidade Global [cited 2016 jul 05]. Rio de Janeiro (Brasil): Fórum das Organizações Não-Governamentais; 1992. Available from: http://portal.mec.gov.br/secad/ arquivos/pdf/educacaoambiental/tratado.pdf.

TRISTÃO M. A educação ambiental na formação de professores: redes de saberes. 2st ed. São Paulo: Annablume; 2008.
VASKE JJ, KOBRIN KC. [Place Attachment and Environmentally Responsible Behavior]. The Journal of Environmental Education [Internet]. 2001[cited $2019 \mathrm{feb}$ 18];32(4):16-21. Available from: https://www.tandfonline. com/doi/abs/10.1080/00958960109598658. English. Doi: $10.1080 / 00958960109598658$. 